\title{
Phenytoin-induced Stevens-Johnson syndrome with myocarditis: a rare case report
}

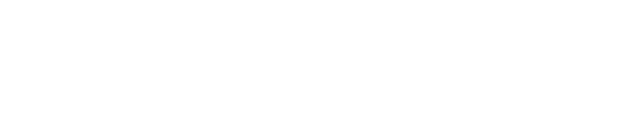

\section{Ashwin Kodliwadmath \\ Department of Medicine, Belgaum Institute of Medical Sciences, Belgaum, India}

\begin{abstract}
Stevens-Johnson syndrome (SJS) is an acute life-threatening mucocutaneous reaction caused by excessive necrosis and detachment of the epidermis. It is commonly drug induced and phenytoin is a common precipitant. Phenytoin, an antiepileptic drug, is also known to cause myocarditis. Phenytoin causing both myocarditis and SJS in the same patient is very rare and can lead to increased morbidity and mortality. Here, we describe the case of a 43-year-old male who developed SJS and myocarditis secondary to phenytoin. In spite of aggressive resuscitative efforts, the patient could not be revived. Thus, a combination of myocarditis with SJS increases the mortality and should be considered in patients with SJS secondary to phenytoin and associated shock.
\end{abstract}

Keywords: phenytoin, myocarditis, Stevens-Johnson syndrome

\section{Introduction}

Stevens-Johnson syndrome (SJS) and toxic epidermal necrolysis (TEN) are mucocutaneous cell-mediated hypersensitivity reactions that are generally rare, but potentially life threatening and commonly drug induced. ${ }^{1,2}$

Because of the similarities in clinical, histopathologic findings, risk factors, and drug causality, these two conditions are now considered severe variants of an identical process that differs only in the final extent of the body surface involved. ${ }^{3}$ Incidence of SJS and TEN is estimated to be approximately one to six cases per million personyears. It can occur at any stage, with the incidence increasing after the fourth decade. ${ }^{3}$ Phenytoin is the most commonly prescribed antiepileptic drug in adults. It is also among the drugs causing the highest rate of cutaneous adverse reactions. ${ }^{4}$ In a case-control study of 73 SJS patients taking antiepileptic drugs, 14 patients were reported with SJS associated with phenytoin ingestion. ${ }^{1}$

Drug-induced hypersensitivity syndrome can involve the heart and cause myocarditis. It usually occurs within 8 weeks of initiation of the new drug. Common agents include antiepileptics, antimicrobials, and allopurinol. Diffuse myocardial involvement causes hypotension and thromboembolic events. Cardiac Magnetic Resonance Imaging and cardiac biomarker measurement help in identifying patients with cardiac involvement. ${ }^{5}$

Here, we describe a very rare case where phenytoin was implicated in causing both SJS and myocarditis.

\section{Case report}

A 43-year-old male who was diagnosed of epileptic disorder and was put on tablet phenytoin $100 \mathrm{mg}$ thrice daily 10 days earlier presented with sudden onset of fluid-filled 
lesions that increased in number and surface area in 2 days. The patient was not on any other drugs. Blisters started bursting out releasing watery fluid. He developed fever, easy fatigability, and breathlessness, which progressively increased. On the fourth day following the onset, his symptoms worsened and he was brought to our hospital.

On evaluation at the emergency room, the patient was in severe respiratory distress and was gasping for breath. He was unconscious and not responding to deep stimuli. Saturation was low; blood pressure was not recordable. He was immediately intubated and put on mechanical ventilation (Figure 1). Inotropes were started.

He had multiple ruptured bullae all over the body and erythematous skin. Oral and conjunctival mucosae were also involved (Figure 2). Dermatology opinion was sought. More than $30 \%$ of the body surface area was involved. Provisional diagnosis of SJS was made. Investigations revealed elevation in cardiac biomarkers. Echocardiogram revealed global hypokinesia. Prothrombin time was 15 s. Activated partial thromboplastin time was 32 s. Platelet count was $143,000 \mathrm{~L} / \mathrm{mm}^{3}$. Results of liver function tests were normal.

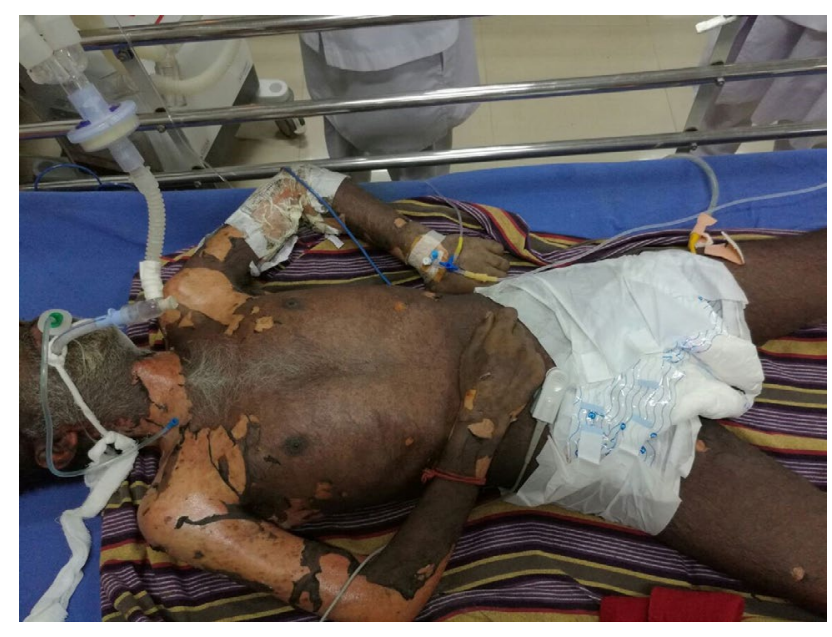

Figure I Image showing the patient incubated with evidence of extensive involvement of the skin of neck and limbs.

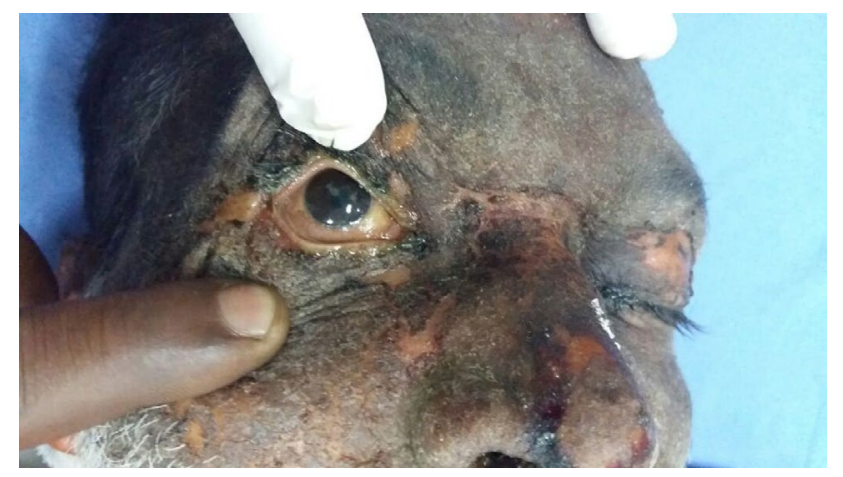

Figure 2 Image showing Stevens-Johnson syndrome invading the mucus membrane of the eyes.
He was given appropriate ICU care by the critical care team. Inotropes were continued. Hydrocortisone $100 \mathrm{mg}$ injection was started after discussion with the dermatologist. Myocarditis was managed conservatively. He was switched over to capsule sodium valproate $1000 \mathrm{mg}$ twice a day.

Twelve hours following admission, his renal parameters were deranged. With full inotropic support, his blood pressure was 80/60 mmHg. Glasgow coma scale score was 4/15.

Near-normal leukocyte count excluded sepsis as a cause for hypotension.

He showed no improvement in clinical and biochemical parameters during the treatment.

After about 18 hours of admission, he had a sudden cardiac arrest and was revived. After an hour, he sustained one more cardiac arrest but could not be revived this time and was declared dead.

\section{Discussion}

SJS is one of the most debilitating adverse drug reactions recognized..$^{6,7}$ Both SJS and TEN are debatably included in the same spectrum as erythema multiforme. This mucocutaneous condition shows similarities in clinical presentation to SJS/ TEN but exhibits some distinct differences. ${ }^{8,9}$ The mortality rate mainly depends on the age and health of the patient, and the rates can range from $30 \%$ to $100 \%$. Individuals at the opposite ends of the age spectrum are usually fatal cases..$^{10,11}$

Although the majority of cases are idiopathic, the main class of known causes is medication, followed by infections and, rarely, cancers. ${ }^{12} \mathrm{~A}$ idiosyncratic, delayed, hypersensitivity reaction has been implicated in the pathophysiology of SJS. We believe that this is the first report of hypersensitivity to phenytoin associated with myocarditis that resulted in mortality beyond SJS.

Magnetic resonance imaging of the head could not be done to evaluate the cause of the seizers as the the patient was critically ill and ventilator dependent. Hypotension was managed only with inotropes. Extracorporeal membrane oxygenation was not available in our hospital.

\section{Conclusion}

SJS caused by drugs, usually antibiotics and antiepileptics, is reported often from many parts of the world. Phenytoin, being one of the mainstays of treatment for a variety of seizure disorders, is extensively used in most of the countries and is cost-effective also. It is also among the drugs causing the highest rate of cutaneous adverse reactions. ${ }^{4}$ Hypersensitivity to phenytoin is not unusual. Early recognition and prompt treatment with corticosteroids might improve the outcome. Also, patient education regarding the possibility of adverse 
drug reaction is essential. Rare association of myocarditis with or without SJS is to be kept in mind.

\section{Acknowledgment}

I would like to acknowledge Dr Kiran Bheemeshwar, Resident, Adichunchanagiri Institute of Medical Science, Bellur, Karnataka, India, for the assistance in preparation of this manuscript.

Written informed consent was taken from the patient's wife for publication of this case report and images.

\section{Disclosure}

The author reports no conflicts of interest in this work.

\section{References}

1. Rzany B, Correia O, Kelly JP, Naldi L, Auquier A, Stern R. Risk of Stevens-Johnson syndrome and toxic epidermal necrolysis during first weeks of antiepileptic therapy: a case-control study. Study Group of the International Case Control Study on Severe Cutaneous Adverse Reactions. Lancet. 1999;353(9171):2190-2194.

2. Kandil AO, Dvorak T, Mignano J, Wu JK, Zhu JJ. Multifocal StevensJohnson syndrome after concurrent phenytoin and cranial and thoracic radiation treatment, a case report. Radiat Oncol. 2010;5:49.

3. Wolff K, Goldsmith LA, Katz SI, Gilchrest BA, Paller AS, Leffell DJ, editors. Fitzpatrick's Dermatology in General Medicine. 8th ed. New York, NY: McGraw-Hill; 2012: 437-440.
4. Chan R, Wei CY, Chen YT, Benet LZ. Use of the Biopharmaceutics Drug Disposition Classification System (BDDCS) to help predict the Occurrence of idiosyncratic cutaneous adverse drug reactions associated with antiepileptic drug usage. AAPS J. 2016;18(3):757-766.

5. Leslie T, Cooper JR, Kirik UK edited by Douglas L Mann, Douglas P Zipes, Peter Libby, Robert O Bonow; founding editor and online editor Eugene Braunwald. Braunwald's Heart Disease: A Textbook of Cardiovascular Medicine. Philadelphia, PA: Elsevier/Saunders; 2015: 1592.

6. Madaiah A, Gowda HN. Fatal phenytoin induced Stevens-Johnson syndrome in an elderly person with metastatic lung carcinoma. Natl $J$ Physiol Pharm Pharmacol. 2016;6:175-177.

7. Cheriyan S, Patterson R, Greenberger PA, Grammer LC, Latall J. The outcome of Stevens-Johnson syndrome treated with corticosteroids. Allergy Proc. 1995;16(4):151-155.

8. Roujeau JC, Guillaume JC, Fabre JP, Penso D, Flechet ML, Girre JP. Toxic epidermal necrolysis (Lyell syndrome). Incidence and drug etiology in France, 1981-1985. Arch Dermatol. 1990;126(1):37-42.

9. Bastuji-Garin S, Rzany B, Stern RS, Shear NH, Naldi L, Roujeau JC. Clinical classification of cases of toxic epidermal necrolysis, Stevens-Johnson syndrome, and erythema multiforme. Arch Dermatol. 1993;129(1):92-96.

10. Yetiv JZ, Bianchine JR, Owen JA Jr. Etiologic factors of the StevensJohnson syndrome. South Med J. 1980;73(5):599-602.

11. Bianchine JR, Macaraeg PV, Lasagna L, et al. Drugs as etiologic factors in the Stevens-Johnson syndrome. Am J Med. 1968;44(3): 390-405.

12. Ward KE, Archambault R, Mersfelder TL. Severe adverse skin reactions to nonsteroidal antiinflammatory drugs: a review of the literature. $\mathrm{Am}$ J Health Syst Pharm. 2010;67(3):206-213.
International Medical Case Reports Journal

\section{Publish your work in this journal}

The International Medical Case Reports Journal is an international, peer-reviewed open-access journal publishing original case reports from all medical specialties. Previously unpublished medical posters are also accepted relating to any area of clinical or preclinical science. Submissions should not normally exceed 2,000 words or
Submit your manuscript here: https://www.dovepress.com/international-medical-case-reports-journal-journal

4 published pages including figures, diagrams and references. The manuscript management system is completely online and includes a very quick and fair peer-review system, which is all easy to use. Visit http://www.dovepress.com/testimonials.php to read real quotes from published authors. 